\title{
ESPACIALIDADE GÓTICA E HORROR EM "SEM OLHOS", DE MACHADO DE ASSIS
}

\section{GOTHIC SPATIALITY AND HORROR IN “SEM OLHOS”, BY MACHADO DE ASSIS}

Renata Philippov ${ }^{1}$

Resumo: Este artigo tem por objetivo analisar o conto "Sem Olhos", de Machado de Assis, pelo prisma da espacialidade gótica, visando a compreender como tal prisma contribui para criar o efeito de horror. Para tal, partindo dos estudos de Botting (1996), Cavallaro (2002) e Punter; Byron (2004) e sobre o gótico, almeja-se discutir como isso se configura no conto machadiano e como este desloca a convençăo gótica de forma irônica.

Palavras-chave: Machado de Assis. Espacialidade gótica. Horror. Ironia.

Abstract: This paper aims at analysing Machado de Assis' short story titled "Sem olhos" from the perspective of Gothic spatiality, with the objective of understanding how such a view helps to create the effect of horror. To this end, this study is based on writings by Botting (1996), Cavallaro (2002), and Punter; Byron (2004), and on the Gothic; thus, discussing how this aspect is configured in Machado de Assis' short story as well as how he ironically displaces the Gothic convention.

Keywords: Machado de Assis. Gothic spatiality. Horror. Irony.

Espaços mal-assombrados ou habitados por fenômenos paranormais fazem parte do imaginário e inconsciente coletivo, constituindo-se enquanto lendas urbanas e presentes no cotidiano de grandes e pequenas cidades, zonas urbanas e rurais, no Brasil e no exterior há séculos. Histórias de apariçōes fantasmagóricas costumeiramente noturnas, muitas vezes em locais que outrora foram cenários de crimes ou mortes inesperadas, fazem parte de um caldo de cultura que, para uns, năo passa de superstiçăo, para outros, de relatos que, embora năo críveis, năo săo tăo absurdos assim, enquanto para outros ainda, sâo sim muito possíveis, pois remetem a crenças religiosas na vida após a morte, por exemplo.

De qualquer forma, acreditando-se nesses fenômenos ou năo, o fato é que sempre há alguém a contar um "causo" sobre isso ou, entăo, a temer entrar em lugares considerados mal-assombrados, como cemitérios, velhas casas sombrias, becos escuros tarde

1 Professora Associada do Departamento de Letras, área de Língua Inglesa e Literaturas de Língua Inglesa, na Escola de Filosofia, Letras e Ciências Humanas da Universidade Federal de Sáo Paulo. Credenciada no Programa de Mestrado em Letras nessa mesma instituiçăo.E-mail: renataph@uol.com.br. 
da noite, locais pouco habitados ou mal iluminados, terrenos descampados, bosques ou florestas densas. Mediante quaisquer ranger de portas, barulhos aparentemente inexplicáveis, e o arrepio já surge, o coraçăo dispara, a perna treme e a vontade de fugir toma conta do indivíduo, seja ele crédulo ou năo.

Diante disso, náo é de se espantar que artistas, cineastas e escritores tenham desde há muito se apropriado dessas crenças e, ao mesmo tempo, alimentando-as por meio da literatura, do cinema, das artes visuais, da música, etc. Assim, o medo da morte sentido pelo homem medieval aparece em seus relatos, suas lendas, seu imaginário, fenômeno que nâo se restringiu àqueles tempos, tendo chegado até nós, cidadâos do século XXI e a nossa cultura. Podemos elencar traços historicamente marcados disso, como o medo da morte ou o medo do desconhecido, por exemplo, na literatura, com relatos de casas mal-assombradas sendo vistos em A volta do parafuso, de Henry James, O Iluminado, de Stephen King, A Assombraçāo da Casa da Colina, de Shirley Jackson, O Morro dos Ventos Uivantes, de Charlotte Brontë, para citar apenas alguns autores de língua inglesa cujas obras trazem fantasmas e apariçôes ditas "reais", ou obras como Psicose, de Robert Bloch, cujos fantasmas podem ser descritos como os fantasmas da mente humana que afloram do inconsciente em momentos de sonhos, vigílias ou ausência de controle racional (segundo uma leitura psicanalítica freudiana ${ }^{2}$ ). Constitutivos do universo dito de horror, tais obras, dentre tantas outras, foram posteriormente adaptadas para o cinema e os quadrinhos, disseminando seus temas, enredos e, assim, fomentando esse caldo de cultura e atingindo um público cada vez maior, público esse muitas vezes leigo, formado por aficionados por histórias de horror, mas também especialistas no tema, nos autores, na questăo do sobrenatural na literatura e nas artes em geral.

A questăo das casas mal-assombradas é ampla e náo restrita ao universo literário de língua inglesa. Afinal, falar em apariçōes fantasmagóricas nas artes em geral, ou na literatura, em particular, é praticamente sinônimo do gênero gótico, ou, pelo menos, é seu elemento central. Passemos, assim, antes de analisarmos o conto em questáo aqui, a questóes do gênero que nortearăo nossa análise. Particularmente, pensemos na questâo da espacialidade gótica, ligada aos fenômenos de apariçóes fantasmáticas.

De acordo com David Punter; Glennys Byron (2004, p. 259), o gótico está profundamente ligado ao sentido de lugar e centrado no motivo do castelo mal-assombrado. Com origens remontando à arquitetura e suas catedrais góticas, surge na literatura inglesa do século XVIII como forma de contraponto ao empirismo e racionalismo iluministas ainda presentes, como escolha pensada por escritores como Horace Walpole e seu Castelo de Otranto (1764), seguido por vários escritores românticos ingleses da primeira metade do século XIX, tais como Mary Shelley, as irmăs Brontë, Byron, William Blake, Samuel Coleridge. Em suas obras e de acordo com o que Stephen Greenblatt (2012) chama de corrente idealista romântica, embora tal crítico esteja restrito ao período entre 1785 e 1832, tais autores, dentre tantos outros, recorrem ao gótico como topos, espacialidade e atmosfera, em posicionamento ideológico contra o racionalismo ainda presente, tanto em termos estéticos quanto políticos. Nessas obras frequentemente veem-se, por exemplo, personagens e eu-líricos (no caso de poemas) angustiados diante de um contexto hostil, narrativas ambientadas năo mais em castelos, mas sim

2 Cf. Freud, [1932] 1933. 
em mansôes abandonadas, isoladas e decadentes em que conflitos existenciais acabam em destruiçáo e morte, fantasmas concretos ou imaginados (os do passado que insiste em retornar à memória) assombrando a paz dos personagens, uma sensaçáo de horror e medo inexplicáveis e incontornáveis, enfim, toda uma espacialidade em que o destino final acaba por ser o de aniquilaçăo e pavor crescentes.

Definido por Fred Botting (1996)3 como "a escrita do excesso", o gótico, segundo esse crítico,

aparece na horrível obscuridade que assombrava a racionalidade e moralidade do século XVIII. Lança sombras aos êxtases desesperados do idealismo e individualismo românticos e as dualidades insólitas do realismo e decadência vitorianos. Atmosferas góticas - melancólicas e misteriosas - tem repetidamente assinalado o retorno perturbador de passados aos presentes e evocado emoçóes de terror e riso. (p.1)

Assim, de acordo com Dani Cavallaro (2002), pela chave da psicanálise freudiana, o gênero estaria ligado com espectros de medo e, ao mesmo tempo, histórica, sociológica e psicanaliticamente associado à escuridăo cultural e a tudo aquilo que a burguesia oitocentista ascendente mais temia: o irracional, o desconforto, a ausência de controle dentro dos seus próprios lares. Afinal, ambientes góticos e em decadência se contrapunham ao ideal nascente de lar. Nas palavras de Cavallaro,

[a] polêmica de que o Gótico constitui o grande campo representacional onde as dinâmicas do medo săo exploradas é confirmada pela associaçấo histórica de tal discurso com a escuridâo cultural. Embora o assombrador de muitos espaços escuros seja, em senso comum, o fantasma, a visăo gótica também é assombrada pelas conotaçóes pejorativas trazidas por "Gótico" como termo estilístico. Dentre as várias localidades infestadas por espectros retratadas pela ficçăo de trevas, a arquitetura gótica enquanto conceito estético é permeada por subtons inquietantes devido a sua conexăo convencional com a barbárie. Os edifícios classificados como "Góticos" sâo aqueles erguidos na Idade das Trevas sobre as ruínas da civilizaçăo clássica. Como termo arquitetônico, o Gótico entrou no léxico ocidental no século XVIII, em um tempo em que o conceito de "lar" estava começando a refletir os valores da burguesia ascendente. Passou a significar tudo o que uma residência de classe média deveria desdenhar: desconforto, frieza, extravagância, limites evanescidos entre o interior e o exterior, e, acima de tudo, estruturas esparsas sugestivas de falta de controle sobre o próprio espaço de alguém. Ao recorrer a castelos longínquos e mansōes labirínticas, as narrativas da escuridâo desafiam o ideal burguês do lar protetor. Edifícios, entâo, tornam-se formas de comentar sobre a política de classes, política de gênero e estruturas relativas a poder e conhecimento. Frequentemente retratam, de forma mais ou menos elíptica, os espaços rejeitados por culturas inteiras. Uma casa mal-assombrada é o lugar/local para onde as ansiedades coletivas convergem. (op.cit, p. 85-86)

No entender dessa estudiosa, é possível compreender o espaço gótico mal-assombrado como lócus em que o novo e o velho, a elite decadente e a burguesia ascendente, respectivamente, estariam em conflito, como se esse velho retornasse e assombrasse incessantemente o novo. Ao discutir exemplos de narrativas como A volta do parafuso,

3 Todas as traduções das citações de cunho teórico são minhas. 
de Henry James (1898), em que "uma casa assombrada [seria] o símbolo de uma sociedade inteira reprimida por um ethos repressivo de decoro" (p. 86), Cavallaro argumenta que a própria problemática dessa novela estaria ligada a esse conflito, a esse clima de ansiedade coletiva entre patróes e empregados. Assim, o espaço gótico condensaria, mimeticamente, tais conflitos de classe, geradores de um medo aniquilador e de angústias há muito reprimidas e em luta interna para se liberarem das amarras do inconsciente humano.

Assim, remontando ao gótico medieval, com suas catedrais e castelos soturnos, ambientes presentes nos romances do século XVIII, diz-nos Botting, referindo-se ao escritor Ambrose Bierce: "casas mal-assombradas predominam como locais sombrios nos quais o passado retorna para perturbar o presente. $O$ mal e a transgressăo săo gentilmente sugeridos em tais assombraçôes e a atmosfera é mais de melancolia e fascínio mórbido". (BOTTING, op.cit, p. 103). Ou ainda, logo no início de seu estudo, afirma o crítico:

o principal lócus de enredos góticos, o castelo era melancolicamente predominante nas origens da ficçâo gótica. Decadente, sombrio e repleto de passagens escondidas, o castelo era ligado a outras construçóes medievais - abadias, igrejas e cemitérios especialmente - que, em seus estados geralmente em ruínas, retornava para um passado feudal associado à barbaridade, superstiçăo e medo. (p. 2)

Mais adiante em seu texto, diz Botting:

em meados do século dezenove há uma difusăo significativa de traços góticos através da ficçăo literária e popular, em meio às formas realistas, romances de sensaçăo e histórias de fantasma especificamente. A maquinaria gótica do século dezoito e as paisagens selvagens do individualismo romântico dăo lugar a terrores e horrores que estâo muito mais próximos aos lares, interrupçóes insólitas das fronteiras entre o interior e o exterior, realidade e ilusăo, propriedade e corrupçáo, materialismo e espiritualidade. Esses săo significados pelo jogo de fantasmas, duplos e espelho. (p. 74)

Assim, segundo tal estudioso, podemos dizer que Machado de Assis teria bebido nesse caldo de cultura estético-literário, de origem inglesa, mas logo expandido para outros países europeus. O autor brasileiro lia em francês e inglês e era leitor ávido, trazendo para seu projeto literário em construçâo aquilo que lhe convinha. Embora um aspecto menos conhecido de suas obras, já que Machado costuma ser lido pela chave dos romances realistas, é possível encontrar em alguns de seus contos pertencentes ao modo literário fantástico ${ }^{4}$ a presença de cenários sombrios, personagens sob sensaçōes claustrofóbicas e de medo desenfreado. Se náo temos em Machado a presença do gótico clássico, o de castelos, masmorras, criaturas maléficas e monstruosas, é no cotidiano brasileiro do século XIX, no Rio de Janeiro e, em alguns casos, em cidades interioranas, mas urbanizadas, que encontraremos personagens vivendo o terror da alma, dentro de uma espacialidade gótica transmutada e adaptada ao contexto em que Machado viveu.

4 Contrapondo-se á definiçăo de fantástico enquanto gênero e á taxonomia bastante fechada propostas por Todorov (1980), para quem o fantástico era domínio da literatura europeia oitocentista e voltada para algumas características bastante rígidas propostas por tal crítico, Ceserani (2006) compreende o fantástico como modo literário e, portanto, passível de ser reconhecido desde a Antiguidade Clássica, com Apuleio e seu "Asno de Ouro" e chegando aos nossos dias, expandindo suas fronteiras para além dos limites geográficos europeus. 
Assim, como veremos a seguir, temos menos castelos do que ricas mansôes e apartamentos em franco declínio, fantasmas reais transmutados em apariçōes etéreas que somente o narrador ou a personagem podem ver e que, talvez, năo passassem de frutos de uma imaginaçăo perturbada, de alguém aterrorizado, de uma mente perdida em si mesma. Nesse sentido, nem sempre temos a casa mal-assombrada, mas sim espaços mal-assombrados. Vejamos o caso de "Sem Olhos", publicado no Jornal das Famílias em dezembro de 1876.

Recorrendo a uma narrativa em moldura, pela qual uma narrativa inclui outra, o conto inicia-se em um evento corriqueiro e aparentemente sem maior relevância para a história: um encontro de amigos à hora do chá. Logo no primeiro parágrafo, temos uma conversa corriqueira e, sem qualquer sobressalto maior ou mudança de tom, o anúncio do tema central de sua conversa:

O chá foi servido na saleta das palestras íntimas às quatro visitas do casal Vasconcelos. Eram estas o Sr. Bento Soares, sua esposa D. Maria do Céu, o bacharel Antunes e o desembargador Cruz. A conversa, antes do chá, versava sobre a última soirée do desembargador; quando o criado entrou, passaram a tratar da morte de um conhecido, depois das almas do outro mundo, de contos de bruxas, finalmente de lobisomem e das abusóes dos índios. (ASSIS, [1876] 2008, p. 1443)

Esse primeiro parágrafo já traz em si a marca machadiana da ironia, aliando um encontro banal - o chá entre amigos - ao tema do sobrenatural, aqui já igualmente banalizado, como se qualquer outro tema pudesse ter sido trazido à baila, mas, por uma mera associaçăo de ideias causada pela mençăo à morte de um conhecido, passam a discutir temas insólitos, sem, no entanto, maiores explicaçóes ou mudança de tom da conversa. O tema das abusōes - termo hoje pouco usual, mas sinônimo de ilusōes, erros de percepçấo, do campo da superstiçăo ou crendice - permanece sendo discutido por parte do grupo, ainda sem maiores desdobramentos, enquanto as senhoras e um dos convidados, o bacharel Antunes, conversam sobre cores de vestidos. Até esse momento, a narrativa ainda traz leveza e trivialidade. No entanto, o tom de voz mais alto de um dos senhores que ainda conversava sobre abusôes humanas chama a atençâo de todos: era Bento Soares, contestando a credulidade do desembargador, que dizia acreditar em coisas sobrenaturais. É quando a conversa passa única e exclusivamente a girar em torno dessa temática: enquanto Cruz defende seu ponto de vista, os demais revezam-se nos papeis de incrédulos e, ao mesmo tempo, interessados no tema. O desembargador, entâo, revela ter visto algo sobrenatural, mas reluta, a princípio em dar detalhes. Após certa insistência dos demais, decide lhes contar fatos que ele mesmo havia vivido, há muito tempo, embora deles se lembrasse com exatidăo, para ilustrar sua crença na existência de fantasmas.

Temos entâo o início da segunda narrativa, relatada de memória pelo agora desembargador, acerca da época em que era um jovem estudante de direito em Sáo Paulo e que, nas férias, por questôes amorosas, costumava passar temporadas no Rio de Janeiro, até que decidiu mudar-se para um andar de uma casa na rua da Misericórdia, nessa mesma cidade, acompanhado por um pajem. O jovem ficou sabendo que havia um só vizinho no imóvel, morador do andar de cima, espécie de sótâo da casa, mas nâo o conhecia, a nâo ser por vê-lo passar de relance, subindo as escadas.

Uma noite, tarde da noite, foi surpreendido por esse vizinho. Tratava-se de um 
homem bem mais velho, com um livro na mâo, e que se pôs a lhe perguntar se era estudante, se sabia hebraico e se podia dirimir uma dúvida sobre uma passagem bíblica do livro de Jonas. Entrou, entăo, com o livro na máo e se sentou na sala, sem ser convidado nem se apresentar. Assim o descreve Cruz, logo após o visitante ter dito que estava interessado em ler o texto bíblico:

Dizendo isto, sentou-se abrindo o livro sobre os joelhos. Joelhos chamo eu, porque é esse o nome daquela regiăo; mas o que ele tinha naquele lugar das pernas eram dois verdadeiros pregos, tâo magro estava. A cara angulosa e descarnada, os olhos cavos, o cabelo hirsuto, as máos peludas e rugosas, tudo fazia dele um personagem fantástico. (p. 1446)

Ou seja, logo o leitor começa a formar a imagem de um homem de aparência espectral, decadente, uma criatura que parecia saída de um relato sobrenatural. O jovem de pronto achou que o vizinho fosse "doido" (p. 1446) e precisou controlar o riso. A conversa entre eles nâo teve sentido algum, embora tenha sido longa e irritante para o jovem. Somente ao final de suas elucubraçóes foi que Cruz ficando sabendo o nome do visitante, Damasceno Rodrigues, o qual, por sua vez, năo lhe deu oportunidade de se apresentar e foi embora assim como chegou, de forma inesperada e inoportuna. Passado o impacto da visita desconexa, o jovem resolveu visitá-lo alguns dias depois. A impressăo do imóvel ocupado pelo vizinho foi de choque:

O segundo andar era antes um sótăo puxado à rua; compunha-se de uma sala, uma alcova e pouco mais. Achei-o na sala, estirado em uma rede, a olhar para o teto. Tudo ali era tăo velho e alquebrado como ele; três cadeiras incompletas, uma cômoda, um aparador, uma mesa, alguns farrapos de um tapete, ligados por meia dúzia de fios, tais eram as alfaias da casa de Damasceno Rodrigues. As janelas, que eram duas, adornavam-se com as cortinas de chita amarela, rotas a espaços. Sobre a cômoda e a mesa havia alguns objetos disparatados; por exemplo, um busto de Hipócrates ao pé de um bule de louça, três ou quatro bolos, meio pote de rapé, lenços e jornais. No chăo também havia jornais e livros espalhados. Era ali o asilo do vizinho misterioso. (p. 1447)

A longa descriçăo revela, para além de certa excentricidade e pobreza de recursos, o lar de uma pessoa vivendo em local muito lúgubre, em ambiente inóspito, remetendo o leitor do conto para a espacialidade gótica e de decadência. Nesse cenário os dois novamente conversaram sobre temas sem nexo, desta vez, além do retorno ao tema bíblico, sobre dúvida de Damasceno acerca de ser a lua habitada ou nâo. Da conversa, ficou a impressâo de desvario por parte do mais velho e da sensaçáo do mais jovem de ter escapado de algum perigo por ter conversado com "uma alma sem consciência [...] um homem sem juízo" (p. 1449). Após essa segunda conversa, passados quinze dias em que se viram no corredor uma ou duas vezes, rapidamente, o jovem foi avisado pelo seu pajem que Damasceno havia por ele procurado insistentemente para lhe confiar um segredo. Diante desse fato e acreditando que tudo năo passasse de "alguma nova fantasia semelhante à de Jonas e à da lua" (p. 1499), Cruz decidiu ignorar tal fato. No entanto, tarde da noite ouviu um gemido vindo do andar de cima e resolveu subir para ver o que estava acontecendo. Nada ouvindo atrás da porta, igualmente nada vez.

No dia seguinte, ao saber que Damasceno estava doente, resolveu visitá-lo e lhe oferecer ajuda. Encontrou-o deitado e sugeriu chamar um médico. De repente, Damasceno sentou-se na cama e, aflito, proferiu as seguintes palavras: “- Năo! Ainda năo! Vai-te! 
Depois, daqui a um ano!...a dois...a três...Vai-te, Lucinda! Deixa-me!" (p.1449) O narrador entâo verificou que estava com febre e mandou chamar um médico. Ao retornar ao quarto, à noite, e encontrando o enfermo melhor, continuaram conversando em torno do tema da morte, já que Damasceno acreditava que sua melhora seria meramente passageira. Passou a filosofar a esse respeito e Cruz decidiu passar a noite a seu lado, velando por seu sono. Logo o tema da conversa passou a ser, em tom de conselho por parte do mais velho para o mais moço, o risco de se olhar para uma mulher comprometida. Foi entâo, sob a parca luz de velas, tarde da noite, que Damasceno resolveu contar seu segredo. Novamente o leitor está diante de uma narrativa em moldura, desta vez uma terceira narrativa dentro das duas anteriores.

Aos poucos, Cruz teve acesso a uma caixinha onde havia "papéis de família" em maço envolvendo "uma miniatura" com "uma formosa cabeça de mulher, e os mais expressivos olhos que jamais contemplei na minha vida" (p. 1452), nas palavras de Cruz. Após lhe pedir que queimasse esse material quando morresse, Damasceno lhe contou seu grande segredo: quando jovem, em localidade distante e rural na Bahia, em Jeremoabo, frequentava a casa de um amigo bastante rude, muito ciumento, e casado com uma mulher lindíssima, mas muito casta e sempre receosa do marido, a ponto de nunca olhar nos olhos de outros homens. Um dia, entretanto, entreolharam-se, Damasceno e ela, Lucinda, algo extremamente rápido, mas presenciado pelo marido. Diante da fúria deste, Damasceno foi forçado a sair da propriedade e sumir por uns dias, receoso de que algo de mal tivesse acontecido a Lucinda. Ao retornar após algumas semanas, diante de boatos de que a mulher havia desaparecido ou morrido, encontrou o marido mais tranquilo e exigiu saber notícias dela. 0 marido, entăo, procurou tranquiliza-lo de que ela ainda estava viva, mas à morte e que ele havia decidido se vingar da causa de sua desonra: os olhos de Lucinda. Damasceno, entăo, aterrorizado, percebeu que o marido havia lhe vazado os olhos com um ferro em brasa.

Cruz ouvia tal relato com horror e repulsa e via seu interlocutor fisicamente cada vez mais cadavérico, mas "admirava a perfeita lucidez com que ele me referia aquelas coisas, a comoçáo da palavra, que nada tinha do vago e desalinhado da palavra dos loucos" (p. 1453). De fato, ocorria exatamente o contrário do que se esperava: um discurso lógico, lúcido, pausado proferido por um homem definhando cada vez mais, tarde da noite, em quarto escuro, com velas quase apagando, sem nenhuma outra testemunha no local. Enquanto isso, Cruz aguardava pelos amigos, médicos, que tardavam a chegar. Diante do desespero, o jovem, "aterrado do que ouvia e da expressăo de sincero horror e aparente veracidade com que ele falava" (p. 1454), queria fugir de lá, quando o clímax da cena entăo aconteceu: Damasceno, pela segunda vez, dirigiu-se a outra pessoa no quarto, uma mulher, implorando, exaltado, para que ela nâo o levasse ainda. Foi entâo que Cruz a viu, atônito, igual à cabeça da miniatura que havia pegado nas măos, mas sem os olhos, que haviam cedido lugar a "duas cavidades vazias e ensanguentadas" (p.1454).

Diante de um horror absoluto, Cruz desmaiou, acordando mais tarde em seu quarto, já com "o sol alto" (p. 1454), cercado dos amigos a quem havia mandado chamar. Soube que o velho falecera ao amanhecer, enquanto falava "das mais desencontradas coisas: de guerras, de meteoros e de S. Tomás de Aquino. Seu último gesto foi para abraçar o sol, que dizia estar diante dele" (p. 1455). Passado o enterro, do qual năo pode participar por estar ainda abalado diante dos acontecimentos daquela noite, e sua tentativa 
de relatar aos mais próximos o que lhe havia acontecido, Cruz resolveu publicar "a catástrofe de Damasceno" (p. 1455) no jornal estudantil de onde estudava. Com tal intuito, prosseguiu a uma pesquisa e descobriu, "com grande surpresa minha, que ele nunca estivera na Bahia, nem saíra do Sul" (p. 1455), bem como que a miniatura era, de fato, "retrato de uma sobrinha sua, morta solteira" (p. 1455). Ou seja, "[n]âo havia dúvida: o episódio que ele me referira era uma ilusáo como a da lua, uma pura ilusâo dos sentidos, uma simples invençăo de alienado" (p. 1455).

Explicaçâo lógica, de cunho científico, para tudo o que Damasceno dizia e fazia, mas e como explicar a apariçăo que Cruz também tinha visto, indagaram os seus ouvintes, já estando o leitor de volta à primeira das três narrativas em moldura, no salăo de chá da casa dos Soares. Cruz, entâo, responde em tom elevado e com argumentos de retórica:

- Sendo assim, como vi a mulher sem olhos? Esta foi a pergunta que fiz a mim mesmo. Que a vi, é certo, tăo claramente como os estou vendo agora. Os mestres da ciência, os observadores da natureza humana lhe explicarâo isso. Como é que Pascal via um abismo ao pé de si? Com é que Bruto viu um dia a sombra de seu mau gênio?" (p. 1455)

Um de seus interlocutores arrisca, entăo, uma teoria de contágio de desvario por parte do doente, ao que Damasceno aponta para sua preferência pela existência e concretude de Lucinda e dos fatos narrados pelo velho, posto que tal história poderia ser o melhor rival do Otelo shakespeariano. Retornando ao tom com que a narrativa do conto foi iniciada, a ironia machadiana, o leitor vê o conto terminado com o impacto dos fatos junto aos que, incrédulos, haviam dito, logo de saída, que năo acreditavam em fantasmas. Final jocoso após a maior parte da narrativa em moldura estar centralizada no relato dos fatos ocorridos a Cruz, fatos esses permeados por uma ambientaçâo escura (tudo de mais amedrontador se passa tarde da noite, sem outras testemunhas que náo Cruz), sob pouca iluminaçấo (velas apagando), em espaço ornado por mobília decadente (os aposentos de Damasceno), quebrada e desordenada (talvez prenunciado, pelo prisma psicanalítico, a fissura psíquica de Damasceno), como se tudo estivesse suspenso no tempo e espaço. No entanto, temos a passagem do tempo marcada de forma cronológica (cada uma das três narrativas em moldura apresenta-se de forma cronológica, embora, ao mesmo tempo, nâo se saiba quando os fatos aconteceram, já que náo há marcaçâo mais explicita sobre datas). Os espaços em que os fatos se dáo têm marcas contextuais bem definidas: a casa dos Soares, a casa na rua da Misericórdia (a nosso ver, outra marca da ironia machadiana: Cruz tinha que sentir e demonstrar misericórdia pela pobre alma do Damasceno), a propriedade rural na Bahia. Tais marcas de espacialidade e temporalidade ajudam a criar uma rede de verossimilhança, o que ajuda a suscitar, por parte das personagens e do leitor, credulidade diante dos fatos narrados. Além disso, tudo está centrado no desembargador Cruz. Como duvidar de um desembargador, grau elevado dentro da magistratura? Como duvidar de alguém que, como dito mais acima, contava tudo de memória, mas se lembrava de tudo, em detalhes? Como duvidar de um velho que, apesar de sua aparente decrepitude e fragilidade física e psíquica, demonstrava lucidez no relato dos acontecimentos na propriedade rural na Bahia?

Portanto, o conto traz, inseridos em contexto de concretude espaço-temporal - rua da Misericórdia, no Rio de Janeiro - e na voz de um narrador bastante crível (como discutido acima, um desembargador, grau elevado no sistema judiciário, nâo poderia estar 
se levando pela crendice popular ao relatar os fatos que, de memória, lhe viam à mente, e que, por sua vez lhe tinham sido pessoalmente relatados naquela noite, tantos anos antes, quando ainda era um jovem estudante de Direito?), vários elementos pertencentes à fantasmagoria e maquinaria góticas, quer seja pela temática de terror, infortúnio, aniquilaçăo, quer seja pelo encapsulamento espacial (tudo o que Cruz relata se passa em ambientes fechados, escuros, decadentes - no caso dos eventos na casa onde mora e tem por vizinho Damasceno, morador de um apartamento descrito como decrépito e lúgubre - ou entăo, em propriedade rural nos recônditos da Bahia, local de difícil acesso e isolado). Assim, as situaçôes de desespero e infortúnio que ocupam boa parte do conto, durante as duas narrativas inseridas dentro da primeira, na casa dos Soares durante um chá trivial entre amigos, săo, a nosso ver, tributárias, ainda que de forma reconfigurada, da estética gótica, estética essa definida por Punter \& Byron, Botting e Cavallaro, críticos acima mencionados. Ainda que estejamos diante de contextos urbanos e rurais distantes daqueles presentes no gótico medieval ou setecentista, temos aqui a presença do gótico, mesclada a um contexto de concretude e verossimilhança que ajudam a criar a atmosfera de horror, quebrada apenas no começo e final do conto, quando a ironia jocosa machadiana parece "puxar o tapete do leitor" (cf. BELLIN, 2017).

Assim, Machado, a nosso ver, retoma a maquinaria e espacialidade góticas, tăo presentes em narrativas inglesas românticas (cf. GREENBLATT, op. cit), trazendo-as para - Brasil do século XIX. Em vez de castelos mal-assombrados ou calabouços sufocantes, temos em "Sem Olhos" o Rio de Janeiro do século XIX, ambiente urbano, portanto, em que o entâo jovem Cruz conhece o segundo narrador do conto, Damasceno, personagem soturna e decrépita (no dizer do próprio narrador, conforme descriçăo acima mencionada) e, aos olhos do estudante de Direito, lunática, mas que, com riqueza de detalhes, relata-lhe eventos que com ele teriam acontecido, anos antes, em propriedade rural baiana isolada e assustadora. Os acontecimentos narrados tanto por Cruz, de memória, acontecimentos esses, por sua vez, relatados por Damasceno, passam-se em ambientes soturnos, decadentes e tenebrosos, tarde da noite, marcas recorrentes da fantasmagoria gótica. Tal ambientaçâo, característica bastante recorrente da espacialidade gótica europeia setecentista e oitocentista (cf. BOTTING, op. cit), aparece no conto machadiano aqui brevemente elencado como potencializadora da atmosfera de pavor que vai a todos enredando e que culmina com a descriçăo aterradora da presença de uma bela e fantasmagórica mulher cujos olhos teriam sido arrancados por um homem tomado por ciúmes infundados, segundo Damasceno, e que, quando da aproximaçâo da morte deste, teria retornado para buscá-lo rumo à eternidade.

Se a narrativa de Cruz tivesse terminado assim, o conto poderia ser tido como gótico, no estilo europeu, com o fantasma aterrador da morta retornando, em espaço e tempo bastante assustadores, para levar seu amado consigo. No entanto, o final da história revela que tudo năo havia passado de brincadeira jocosa de Cruz durante um chá entre amigos. Damasceno jamais tinha visitado a Bahia ou conhecido a bela mulher casada com marido ciumento; năo havia fantasma algum, portanto, a năo ser um fantasma criado, ao que tudo indica, pela mente do jovem Cruz, aterrorizado e sugestionado pelo relato que ouvia, naquela noite aterrorizante, de um Damasceno à beira da morte e mais insano do que nunca, segundo o Desembargador relatava tantos anos depois. Nesse sentido, ao contrário das narrativas góticas setecentistas e oitocentistas europeias, com finais de aniquilaçăo, destruiçăo e morte, o conto acaba de forma breve e 
leve, como se tudo náo tivesse passado de um sonho, uma brincadeira, uma mentirinha branda, uma abusão ou erro de percepçăo.

Portanto, a nosso ver, ao criar uma narrativa de horror aliada à espacialidade gótica em "Sem Olhos", Machado se apropria, até certo ponto, do caldo de cultura gótico, trazendo-o para seu contexto e, ao mesmo tempo, para seu projeto literário. Nesse sentido, o horror e terror das narrativas góticas tradicionais transmutam-se em algo mais suave, nem que seja bem no final da narrativa, como vimos aqui. Em vez de castelos mal-assombrados, em noites de tempestade e insanidade desenfreada, o conto em questăo traz, com riqueza de detalhes, a espacialidade gótica para o ambiente urbano do Rio de Janeiro ou uma fazenda baiana isolada de tudo e todos. No entanto, a descriçâo de ambientaçâo lúgubre permanece presente no conto, com móveis velhos, pouca luz, noite soturna, apartamento e fazenda descritos como decadentes e assustadores, habitados por personagens lúgubres e irracionais (tanto Damasceno quanto o marido da morta săo descritos como seres desprovidos de razâo). Surge um fantasma, figura recorrente nas narrativas góticas setecentistas e oitocentistas, mas, ao final, revela-se ser imaginário apenas, fruto de uma mente doente e pertencente a um homem em seu leito de morte, homem esse descrito, desde o início, como decrépito e quase um morto-vivo (tâo cadavérico quanto um esqueleto) e de um jovem facilmente sugestionável diante dos relatos insanos do moribundo. $O$ tom é retomado ironicamente a partir da convençăo ou tradiçăo góticas, deslocado de macabro para jocoso, de lúgubre para irônico/sarcástico, e deixando personagens e o leitor no ar diante da incerteza dos acontecimentos.

Ao final da narrativa, cabe a cada um dos participantes daquele chá entre amigos, em tarde inicialmente aprazível e banal, decidir entre crer ou năo crer nos eventos narrados, diante de uma teia na qual todos foram enredados desde o início, teia essa suscitando em quem a ouve, na conversa durante aquele dia agradável, um sentimento de pavor, mesmo sentimento sentido por Cruz, quando jovem, diante dos relatos de Damasceno, que, segundo este próprio, também sentira esse mesmo sentimento na fazenda nos confins da Bahia. Somente ao final da narrativa em moldura, desfaz-se essa teia e se corrige o erro de percepçăo, erro esse que olhos, ou talvez, melhor dizendo, a ausência de olhos atentos induziu ao entăo jovem estudante de Direito e aos convidados do chá da tarde a cometerem. Nesse sentido, o próprio título da narrativa seria aplicável náo apenas à mulher fantasmagórica inventada pela mente doentia de um moribundo e vista por um jovem facilmente sugestionável, mas também, de forma irônica, às personagens todas e à série de eventos narrados pelo Desembargador Cruz e inventados por Damasceno, em seu leito de morte. A nosso ver, portanto, desde o título do conto, Machado estaria jocosamente avisando aos leitores que a ausência de olhos induz a erro de percepçâo e a acreditar no irracional e que, mesmo um representante do judiciário, figura respeitável e crível, dada sua posiçâo social, pode ser induzido a erro e a crer em crendices, ainda que isso tenha acontecido durante sua juventude. Erro esse, por sua vez, suscitado em grande parte pela fantasmagoria e espacialidade góticas presentes no conto, desde o momento em que Cruz começa a narrar os eventos que lhe teriam acontecido, tantos anos antes. 


\section{REFERÊNCIAS}

ASSIS, J. M. M. Sem Olhos. In: Obra Completa. Vol. 2: Conto. Rio de Janeiro: Nova Aguilar, 2008, p. 1443-1456.

BELLIN, G. Machado de Assis leitor de Poe: a retomada irônica da convençăo gótica no conto "Um Esqueleto". In: SILVA, A.M.; BARROS, F.M.; COLUCCI, L. (org.). Estudos do Gótico. Rio de Janeiro: Dialogarts, 2017. Disponível em: http://www.dialogarts.uerj.br/ admin/arquivos tfc literatura/Livro_Estudos do gotico_ff.pdf. Acesso em: 03 jun.2018.

BOTTING, F. Gothic. London: Routledge, 1996.

CAVALLARO, D. The Gothic Vision: Three Centuries of Horror Terror and Fear. London: MPG Books Ltd, 2002.

CESERANI, R. O fantástico. Traduçâo Cesar Tridapalli. Curitiba: UFPR/ EDUEL, 2006.

FREUD, S. Conferência XXII: Revisăo da Teoria dos Sonhos. In:___Novas Conferências Introdutórias sobre Psicanálise e outros trabalhos (1932-1936). Obras completas, v. XXII. Rio de Janeiro: Imago Editora, 1996.

GREENBLATT, S. (ed.) Introduction. In:

The Norton Anthology of English Literature - The Romantic Period, volume D. Ninth edition. New York: W.W. Norton \& Company, 2012, p. 3-29.

PUNTER, D.; BYRON, G. The Gothic. Malden, MA: Blackwell Publishing, 2004.

TODOROV, T. Introduçâo à literatura fantástica. Traduçăo Maria Clara Correa Castello. Săo Paulo: Perspectiva, 1980.

Submetido em 24 de março de 2018 Aceito em 16 de julho de 2018 